\title{
Validity and Reliability of Three Rating Scales to Assess Practitioners' Skills to Conduct Collaborative, Strength-Based, Systemic Work in Family-Based Services
}

\author{
ANA TEIXEIRA DE MELO, MADALENA ALARCÃO, \\ and INÊS PIMENTEL \\ Faculty of Psychology and Education Sciences, University of Coimbra, Coimbra, Portugal
}

\begin{abstract}
This study analyzed the reliability and validity of three rating scales designed to assess practitioners' skills in conducting systemic, collaborative, and strength-based assessments and interventions with multi-challenged families in family-based community services. The three scales, which assess reception and assessment skills, basic skills, and skills to support change, revealed good psychometric properties considering their construct validity, internal consistency, and inter-rater agreement. The results are discussed considering future research and possible applications of the scales in research and practice.
\end{abstract}

\section{INTRODUCTION}

Contributions from different models and traditional schools of family therapy are often integrated in family therapy training programs and manuals and in professionals' practice (Garven \& White, 2009; Nichols \& Schwartz, 2001; Pote, Stratton, Cottrell, Shapiro, \& Boston, 2003; Smith \& Southern, 2005). Training in family therapy is starting to reflect a more outcome and competencies focused orientation (Nelson et al., 2007; Nelson \& Smock, 2005). This orientation has been associated with the development of

The present work was supported by a doctoral scholarship (SFRH/BD/39912/2007) attributed to the first author by the Foundation for Science and Technology, Portugal. The authors wish to thank all the practitioners and families who collaborated with data collection and all the raters who collaborated in the first stage of the scale and scoring manual development.

Address correspondence to Ana Isabel Martins Teixeira de Melo, Apartado 1562, EC Devesas, 4400-Vila Nova de Gaia, Portugal. E-mail: anamelopsi@gmail.com 
instruments to assess trainees' and therapists' skills (Briggs, Fournier, \& Hendrix, 1998; Nelson \& Johnson, 1999; Perosa \& Perosa, 2010). However, most of these instruments are mostly suited for traditional contexts and formats of family-therapy.

Systemic theories and different family therapy models have influenced different types of family-based services implemented in community settings (e.g., Berg \& Kelly, 2000; Henggeler, Schoenwald, Bourduin, Rowland, \& Cunningham, 1998; Rojano, 2004). In more recent years, strength-based perspectives have also been prominent as a basic conceptualization framework for different ways of working with families (Corcoran, 2005; Smith, 2006). However, the field of family support services is still dominated by deficitbased and expert-drive discourses (Madsen, 2007). Training in systemic, strength-based, and collaborative approaches (e.g. solution-focused, narrative therapies) may be welcomed in the field of family-based services as they are still not the rule (Madsen, 2007; Sousa, Ribeiro, \& Rodrigues, 2007).

Although the field of family therapy has assisted the development and validation of several measures to assess trainees' competencies during training and supervision or for in training research, these instruments do not necessarily reflect collaborative (Hoffman, 1993; Madsen, 2007; Strong, 2002) or strength-based orientations (Berg, \& Kelly, 2000; Corcoran, 2005; Smith, 2006), nor are they suited to assess practitioners' skills from multidisciplinary teams working with families in diverse social, child protection, or familybased services.

The aim of this study is to assess the psychometric properties of three rating scales which are part of a broader set of 5 scales (The Scales for the Assessment of IFAIM's Practitioners' Skills) designed to assess the skills profile of the practitioners implementing the Integrated Family Assessment and Intervention Model (IFAIM). IFAIM is an integrated, systemic and collaborative assessment and intervention model, implemented by community multidisciplinary teams working with multi-challenged families with at-psychosocial risk and in danger, particularly maltreated children (Melo \& Alarcão, 2011). The model is strength-orientated and incorporates contributions from collaborative (narrative and solution-focused) approaches. It is a family-centered approach designed to conduct assessments with multi-challenged families referred by the child welfare and protection systems, in order to produce assessment reports, to support decision making and the elaboration of tailormade support projects, to promote family preservation or reunification, to increase protective factors, and to strengthen families. For this purpose, IFAIM aims to provide multi-systemic, integrative support to facilitate the family's change. Being integrative, the model draws from contributions from different models of family therapy and parenting intervention to support the family's change. It also combines a therapeutic focus with social, educational, and community work. The family's home and the community are the main settings for the implementation of IFAIM, which occurs in different stages 
with specific objectives and procedures detailed elsewhere (Melo \& Alarcão, 2011).

Although the rating scales were specifically designed to support process and outcome training evaluations of the professionals implementing IFAIM, they may be suited for use in the context of any intervention which shares the same principles, orientations, and objectives. The scales are organized according to the main tasks associated with each stage of work prescribed in IFAIM (Melo \& Alarcão, 2011). Nevertheless, they may guide other professionals from the first contacts to assessment and support for change with multi-challenged families with at-risk or maltreated children, respecting systemic, collaborative, and strength-based principles.

The three rating scales included in this study assess three broad categories of skills and are: a) Scale 1- Scale for the Evaluation of Reception and Assessment Skills; b) Scale 2- Scale for the Evaluation of Basic Skills; and c) Scale 3- Scale for the Evaluation of Support for Change Skills. Specifically, this study aims to evaluate these ratings scales in regard to their: a) construct validity; b) internal consistency reliability and c) inter-rater agreement reliability.

\section{METHOD}

\section{Participants}

Ten teams of practitioners working in family support centers in Portugal participated in the study. As a general rule, the teams were composed of 3 female professionals, namely a psychologist, a social worker, and either a social educator or a social animator. All of the teams participated, to different extents, in a training program to implement the Integrated Family Assessment and Intervention Model (IFAIM). One of the team members was a student in family therapy and none were a licensed family therapist, although some had some training experiences in themes of family therapy.

\section{Measures}

Rating Scales and Scoring Manual Development

The three scales included in this study belong to a set of 5 rating scales which compose The Scales for the Assessment of IFAIM's Practitioners' Skills. Each scale corresponds to a broad category of skills which integrates the profile of competencies of IFAIM's practitioners (Melo \& Alarcão, 2008), namely: a) Scale 1- skills related to the reception and assessment stages; b) Scale 2- basic skills in the conduction of family sessions; c) Scale 3- skills related to the support for change stage; d) Scale 4- skills for in-home sessions and e) Scale 5- skills to conduct sessions with other professionals or significant elements. The profile of skills to which the items of the scales correspond 
were previously assessed by an expert panel in regard to their adequacy considering IFAIM's systemic, collaborative and strength-based theoretical orientation. This evaluation, reported elsewhere (Melo \& Alarcão, 2010), provided some initial indirect evidence regarding the content validity of the scales. Moreover, each item was built in direct correspondence to each skill of the skills profile. Results of the study of the psychometric properties of the fourth scale are reported elsewhere (Melo, Alarcão, \& Pimentel, 2011) and the fifth scale has not been yet been studied. Two main stages of the scales' and scoring manual's development followed the initial construction of the items.

In a first stage, and after the elaboration of the items, a brief scoring manual was elaborated with global instructions on how to use the scales and a global description of each rating point. In this first stage, a group of five raters (four women and one man) were involved along with the authors in the revision and improvement of the scales. Of those five raters, four were family therapy students in supervision and the other was a licensed family therapist and family therapy trainer. The group of raters conducted an initial assessment of the items, discussing each one in regard to the adequacy of its formulation and inclusion in each scale, and clarifying what kind of actions should be scored. Afterwards, one calibration meeting (a meeting in which the raters discuss their scorings and disagreements in order to establish uniform scoring criteria and elaborate strategies and/or alterations to the scale or scoring procedures to improve agreement) was held in which all raters completed the corresponding scales scoring practitioners' skills in five sessions through the analysis of their transcriptions. An additional set of two sessions was independently scored after this meeting by the five raters and these scorings were discussed only between the first author and each of the other five raters involved. After this, all five raters and the first author started scoring practitioners' skills and completing the rating scales through analyses of the sessions' transcriptions. The first author rated the sessions pairing with all the other five raters and scorings were discussed with the objective of improving agreement. After rating approximately 10 sessions, the inter-rater agreement remained low and the group concluded for the need of having a clearer definition of each rating point of the scale.

In a second stage of the scales and manual development, a new, more extensive, scoring manual was elaborated containing a clearer and more precise definition of each item/skill. The scoring manual also included, for each item, a detailed description of each rating point with examples of actions which could reflect different levels of mastery of the skill to be evaluated.

Three new sessions were scored by the raters using the new manual and discussed in a second meeting, in which they considered ways of improving agreement. Some additional changes in the formulation of some items and in the scoring procedures were introduced. Three items were removed 
from Scale 3 since there was significant overlap with some of the items in Scale 2 . The group concluded that agreement had significantly improved with the new scoring procedures. After this meeting, one additional session transcription was scored by all raters which confirmed that.

\section{SCALES DESCRIPTION}

Scale 1- Scale for the Evaluation of Reception and Assessment Skills was composed of 12 items (Appendix A) designed to assess some systemic, collaborative, strength and solution based assessment skills. Scale 2- Scale for the Evaluation of Basic Skills had 17 items to assess basic systemic and collaborative skills in the conduction of family sessions (Appendix B). Scale 3Scale for the Evaluation of Support for Change Skills comprehended 11 items designed to evaluate practitioners' skills to facilitate and support change (Appendix C). All items were scored in a 4 point-Likert scale, ranging from 1 , which broadly corresponded to "skill absent/skill incorrectly applied," to 3, which corresponded to "skill present, applied adequately and consistently," Scorings of 0 corresponded to "Not Applicable." The scales' rating manual (Melo \& Alarcão, 2009) comprehends more precise descriptions and examples of what constitutes a scoring of $1,2,3$, or 0 for each item.

\section{Procedure}

Reception, assessment and intervention sessions of the 10 participating multidisciplinary teams were audio or video recorded by the teams. Due to the inexistence of formal Institutional Review Boards in Portugal this research project was not submitted to one. However, informed consent was obtained from the practitioners and families participating in the study. Sessions (178) were collected during the course of approximately three years, before, after and during the team's professional development and training history. Some of the sessions included were conducted by the first author.

All sessions were transcribed verbatim by the first author or by the teams. Procedures were adopted to alter information concerning the identification of the families and the practitioners in order to protect their confidentiality. The sessions' transcripts were read before the completion of the rating scales according to the instruction of the scoring manual. The rating scales were completed for all the sessions by the first author and a sub-sample of sessions was independently scored by one of four other raters, in order to evaluate inter-rater agreement. All raters were women. Three of these raters had been involved in the stages of scale and manual development. The fourth rater participated in separate calibration sessions with the first author. After each set of 5 sessions being scored, the raters compared and discussed their scorings. A total of 108 session's transcription (35 reception and 73 assessment 
sessions) was used to complete Scale 1, of which 53 were independently scored by a second rater. For Scale 2, a total of 174 transcriptions of sessions (35 reception, 80 assessment and 59 intervention sessions) was considered, of which 90 were independently scored by a second rater. For Scale 3, a total of 63 intervention sessions was used, of which 37 were independently scored by a second rater. Since most sessions were conducted by two practitioners, the skills of each practitioner were scored independently and a separate score was completed for the team. In order to simplify the process we decided to perform factor analysis with the ratings scores for only one of the practitioners, but we also wanted to maintain uniform criterion. Since in most sessions the practitioner rated as Practitioner 1 was the one with a more active and leading role in the session, and the ratings for Practitioner 2 were, in many cases, similar, we chose to use the scores of the Practitioner 1.

\section{RESULTS}

In order to assess the scales' construct validity, exploratory Factor Analyses using a principal component solution were computed, followed by varimax rotations. Factors were retained when eigenvalues were superior to one. The analysis of the screenplots confirmed the adequacy of this criterion. In order to assess the scales' internal consistency reliability Alpha of Cronbach statistics were calculated for all the factors/sub-factors obtained in the final factorial solutions for each scale. Inter-rater agreement Cohen's Kappa reliability statistics were calculated for each item. Mean Kappa values were obtained for each factor/sub-scales.

In the Factor Analysis for Scale 1, the Kaiser-Meyer-Olkin measure of sampling adequacy was .84. Table 1 reports the results for Scale 1, which yielded a three factor solution and good reliability values.

In regard to Scale 2, a first factor analysis suggested the retention of four factors with eigenvalues above 1 . Item 17 loaded negatively in the fourth factor along with item 16, which had a positive loading. There were some other items which saturated secondarily. Theoretically, the solution was not sound. Therefore, a second factor analysis was calculated without item 17. This time, a three factor solution was found. However, the set of 4 items (items $7,11,15,16$ ) which loaded on factor 2 yielded an alpha of Cronbach value of .60, which was lower than desired. The removal of any of the items would not improve this value. Since item-total correlations were low (varying from .28 for item 16, .35 for item 7, .42 for item 11 and .47 for item 15) all items were removed and a new factor analysis was computed without them.

The final factor analysis presented a two factor solution and good reliability values, as presented in Table 2 . The Kaiser-Meyer-Olkin measure of sampling adequacy was .85 . 
TABLE 1 Final Factor Solution, Factor Loadings, Alpha of Cronbach, and Inter-Rater Agreement Kappa Reliability for Scale 1

\begin{tabular}{|c|c|c|c|c|}
\hline Item & $\begin{array}{c}\text { Factor } 1 \\
\text { Contract and relationship } \\
\text { negotiation }\end{array}$ & $\begin{array}{c}\text { Factor } 2 \\
\text { Systemic, solution, and } \\
\text { strength-based assessment }\end{array}$ & $\begin{array}{l}\text { Factor } 3 \\
\text { Child } \\
\text { safety }\end{array}$ & $\mathrm{Kappa}^{\mathrm{ab}}$ \\
\hline 1 & .86 & - & - & .87 \\
\hline 2 & .86 & - & - & .85 \\
\hline 3 & .85 & - & - & .80 \\
\hline 4 & .81 & - & - & .82 \\
\hline 5 & - & .40 & -.73 & .63 \\
\hline 6 & .73 & - & - & .75 \\
\hline 7 & .76 & - & - & .77 \\
\hline 8 & .31 & .71 & - & .66 \\
\hline 9 & - & .78 & - & .82 \\
\hline 10 & - & .70 & - & .84 \\
\hline 11 & - & - & .70 & .63 \\
\hline 12 & - & .79 & - & .79 \\
\hline $\begin{array}{l}\text { Variance } \\
\text { explained }\end{array}$ & $38.90 \%$ & $19.14 \%$ & $8.94 \%$ & \\
\hline$\alpha_{\text {Cronbach }}$ & .90 & .76 & - & \\
\hline Mean Kappa ${ }^{a}$ & .80 & .75 & .63 & \\
\hline $\begin{array}{c}\text { Total variance } \\
\text { explained }\end{array}$ & $66.98 \%$ & & & \\
\hline $\begin{array}{l}\alpha_{\text {Cronbach for }} \\
\text { global scale }\end{array}$ & & .85 & & \\
\hline
\end{tabular}

Note. Loadings inferior to .30 were suppressed. Factor loadings in bold indicate the factor to which the item was allocated. $\mathrm{N}=108$ reception and/or assessment sessions.

${ }^{a}$ For a sub-sample $(\mathrm{n}=53)$ for which inter-rater agreement was calculated. ${ }^{\mathrm{b}}$ For all Kappa values, $p<$ .001 .

In regard to Scale 3, a three factor solution was obtained, as evidenced in Table 3. The Kaiser-Meyer-Olkin measure of sampling adequacy was .82.

Again, all sub-scales presented good alpha of Cronbach reliability values and substantial mean Kappa inter-rater agreement. Item-level agreement was lower (.58) for item 9. However, since there was an acceptable item-total correlation (.60) with the factor it was allocated to, and since its removal would lower the alpha of Cronbach value, the item was retained.

\section{DISCUSSION}

This study aimed at assessing the psychometric properties of three rating scales, which reflect a systemic, collaborative, and strength-based orientation, integrated in a broader set of scales named The Scales for the Assessment of IFAIM's (Integrated Family Assessment and Intervention Model) Practitioners' Skills. The results support the scales' construct validity in addition to indicating good internal consistency and inter-rater reliability. The scales are suitable to be used according to the structure reported. Nevertheless, some items had to be removed in scale 2, and item 9 in scale 3 had low 
TABLE 2 Final Factor Solution, Factor Loadings, Alpha of Cronbach, and Inter-Rater Agreement Kappa Reliability for Scale 2

\begin{tabular}{|c|c|c|c|}
\hline Item $^{c}$ & $\begin{array}{c}\text { Factor } 1 \\
\text { Session organization, } \\
\text { collaborative and reflexive } \\
\text { participation }\end{array}$ & $\begin{array}{l}\text { Factor } 2 \\
\text { Emergence and integration of } \\
\text { relational information }\end{array}$ & $\underset{\substack{\text { Kappa } \\
\mathrm{r}_{\mathrm{s}}}}{\operatorname{kb}}$ \\
\hline $1(1)$ & - & .90 & .82 \\
\hline $2(2)$ & .74 & - & $.69^{\mathrm{d}}$ \\
\hline $3(3)$ & - & .92 & .69 \\
\hline $4(4)$ & .65 & - & .75 \\
\hline $5(5)$ & .80 & - & .76 \\
\hline $6(6)$ & .74 & - & .77 \\
\hline $8(7)$ & .64 & - & $.82^{\mathrm{d}}$ \\
\hline $9(8)$ & .62 & .45 & $.84^{\mathrm{d}}$ \\
\hline $10(9)$ & .62 & - & .74 \\
\hline $12(10)$ & .85 & - & .88 \\
\hline $13(11)$ & .52 & - & $.84^{\mathrm{d}}$ \\
\hline $14(12)$ & .80 & - & .64 \\
\hline Variance explained & $44.36 \%$ & $14.79 \%$ & \\
\hline$\alpha_{\text {Cronbach }}$ & .88 & .77 & \\
\hline Mean Kappa ${ }^{a}$ & $.76^{\mathrm{e}}$ & .76 & \\
\hline $\begin{array}{l}\text { Total variance } \\
\text { explained }\end{array}$ & \multicolumn{2}{|c|}{$59.15 \%$} & \\
\hline $\begin{array}{l}\alpha_{\text {Cronbach }} \text { for global } \\
\text { scale }\end{array}$ & \multicolumn{2}{|c|}{.86} & \\
\hline
\end{tabular}

Note. Loadings inferior to .30 were suppressed. Factor loadings in bold indicate the factor to which the item was allocated. $\mathrm{N}=174$ reception, assessment, or intervention sessions.

${ }^{a}$ For a sub-sample $(\mathrm{n}=90)$ for which inter-rater agreement was calculated. ${ }^{\mathrm{b}}$ For all Kappa and Spearman correlation statistics, $p<.001$. ${ }^{\mathrm{c}} \mathrm{A}$ new numeration of the items is proposed between parentheses. ${ }^{\mathrm{d}}$ For these items, it was not possible to compute Kappa statistics since the requirement of constructing a symmetric two-way table to match all the values of the variable for the two raters could not be met since some values were not equally observed by the two raters. Spearman correlation values are reported. esince it was not possible to obtain Kappa statistics for all values, mean Kappa considers only the mean of the items for which it was calculated.

inter-rater agreement. Therefore, future research may consider revising those items and/or their scoring definitions.

It is our consideration that the scales may serve different purposes and deserve future attention. In practice, they may provide some guidance in regard to the main tasks to be performed and the skills to be exhibited by teams in family centers, social or child protection services who wish to help families from a systemic, collaborative and strength-based perspective. The scales can also be used as instruments of hetero and self-evaluation of the professionals' performance and support their progress throughout outcomeoriented training programs.

As research instruments, the scales may be integrated in studies when there are concerns with the fidelity of interventions and in efficacy or effectiveness studies investigating the relation between the professional's skills and the family's change. 
TABLE 3 Final Factor Solution, Factor Loadings, Alpha of Cronbach, and Inter-Rater Agreement Kappa Reliability for Scale 3

\begin{tabular}{|c|c|c|c|c|}
\hline Item & $\begin{array}{c}\text { Factor } 1 \\
\text { Facilitating change } \\
\text { rehearsal and } \\
\text { amplification }\end{array}$ & $\begin{array}{c}\text { Factor } 2 \\
\text { Facilitating change } \\
\text { and overcoming } \\
\text { obstacles }\end{array}$ & $\begin{array}{c}\text { Factor } 3 \\
\text { Elaborating and } \\
\text { contracting a plan for } \\
\text { change }\end{array}$ & Kappa $^{\mathrm{ab}}$ \\
\hline 1 & - & - & .88 & .76 \\
\hline 2 & - & - & .88 & .84 \\
\hline 3 & - & .63 & 47 & .60 \\
\hline 4 & & .64 & .33 & .73 \\
\hline 5 & .87 & - & - & .67 \\
\hline 6 & .85 & - & - & .76 \\
\hline 7 & .58 & - & .51 & .72 \\
\hline 8 & .57 & .66 & - & .92 \\
\hline 9 & .31 & .71 & - & .58 \\
\hline 10 & .45 & .65 & - & .69 \\
\hline 11 & .72 & - & - & .70 \\
\hline $\begin{array}{l}\text { Variance } \\
\text { explained }\end{array}$ & $48.09 \%$ & $12.09 \%$ & $9.76 \%$ & \\
\hline$\alpha_{\text {Cronbach }}$ & .84 & .80 & .91 & \\
\hline Mean Kappa ${ }^{\mathrm{a}}$ & 0.71 & .70 & .80 & \\
\hline $\begin{array}{c}\text { Total variance } \\
\text { explained }\end{array}$ & & $70.79 \%$ & & \\
\hline $\begin{array}{l}\alpha_{\text {Cronbach for }} \\
\text { global scale }\end{array}$ & & .88 & & \\
\hline
\end{tabular}

Note. Loadings inferior to .30 were suppressed. Factor loadings in bold indicate the factor to which the item was allocated. $\mathrm{N}=63$ intervention sessions.

${ }^{\mathrm{a}}$ For a sub-sample $(\mathrm{n}=37)$ for which inter-rater agreement was calculated. ${ }^{\mathrm{b}}$ For all Kappa values, $p<.001$.

This study has several limitations which should be addressed in future research. On the one hand, practitioner's skills were analyzed using the session's transcription, which may have made it difficult for the raters to assess, the adequacy of the scorings in some cases. For example, without detailed information about the previous sessions it could be more difficult to assess the adequacy of "Not Applicable" scorings.

The fact that only the scorings of one rater were considered in the factor analysis is a limitation. It is possible that the internal consistency values obtained reflect the consistency of one rater more than that of the scale. On the other hand, and even though the calibration sessions had in consideration the level of agreement between all raters, the calculation of inter-rater reliability Kappa statistics for the scales was performed with the first rater being always the same. In future studies, inter-rater agreement reliability study should rely on different pairs of raters and compare the professionals' self-evaluation with expert or external evaluations. The study should be replicated with different sorts of interventions and contexts, and with different profiles of practitioners. 


\section{REFERENCES}

Berg, I. K., \& Kelly, S. (2000). Building solutions in child protective services. New York, NY: W. W. Norton \& Company.

Briggs, K., Fournier, D. G., \& Hendrix, C. C. (1998). Evaluating trainees' skill development: The family therapy skills checklist. Contemporary Family Therapy, 21(3), 354-371.

Corcoran, J. (Ed.) (2005). Building strengths and skills: A collaborative approach to working with clients. New York, NY: Oxford University Press.

Garven, R., \& White, H. (2009). Key systemic ideas as seen through the eyes of first-year trainees. The Australian and New Zealand Journal of Family Therapy, 30(3), 196-215.

Henggeler, S. W., Schoenwald, S. K., Bourduin, C. M., Rowland, M. D., \& Cunningham, P. B. (1998). Multisystemic treatment of antisocial behaviour in children and adolescents. New York, NY: The Guilford Press.

Hoffman, L. (1993). Exchanging voices: A collaborative approach to family therapy. London, England: Karnac Books.

Madsen, W. C. (2007). Collaborative therapy with multi-stressed families (2nd. ed.). New York, NY: The Guilford Press.

Melo, A. T. (2008). Apresentação de uma proposta de um modelo global de organização dos CAFAP, no Modelo de Avaliação e Intervenção Familiar Integrada e respectivo plano perfil de competências e plano de formação dos profissionais [Preliminary proposal of a global model of organization for CAFAP, Integrated Family Assessment and Intervention Model and training plan for professionals]. Unpublished manuscript.

Melo, A. T., \& Alarcão, M. (2008). Proposta preliminar de um modelo global de organização dos CAFAP, no Modelo de Avaliação e Intervenção Familiar Integrada e respectivo perfil de competências e plano de formação dos profissionais [Preliminary proposal of a global model of organization for CAFAP, Integrated Family Assessment and Intervention Model and training plan for professionals]. Unpublished manuscript, Faculdade de Psicologia e de Ciências da Educação da Universidade de Coimbra, Coimbra, Portugal.

Melo, A. T., \& Alarcão, M. (2009). Manual de cotação das Grelhas de Avaliação das Competências do Profissional do MAIFI [Scoring manual for the Scales for the Assessment of IFAIM's practitioners' skills]. Unpublished manuscript.

Melo, A. T., \& Alarcão, M. (2010). Avaliação da qualidade do planeamento do Modelo de Avaliação e Intervenção Familiar Integrada para os Centros de Apoio Familiar e de Aconselhamento Parental [Assessment of the quality of planning of the Integrated Family Assessment and Intervention Model for the Centers of Family Support and Parental Counselling]. Psicologia, XXIV(2), 197-218.

Melo, A. T., \& Alarcão, M. (2011). Integrated Family Assessment and Intervention Model: A collaborative approach to support multi-challenged families. Manuscript submitted for publication.

Melo, A. T., Alarcão, M., \& Pimentel, I. (2011). Scale for the assessment of practitioner's basic in-home sessions skills: Validity and reliability. Manuscript submitted for publication. 
Nelson, T. S., Chenail, R. J., Alexander, J. F., Crane, D. R., Johnson, S. M., \& Schwallie, L. (2007). The development of core competencies for the practice of marriage and family therapy. Journal of Marital and Family Therapy, 33(4), 417-438.

Nelson, T. S., \& Johnson, L. N. (1999). The basic skills evaluation device. Journal of Marital and Family Therapy, 25, 15-30.

Nelson, T. S., \& Smock, S. A. (2005). Challenges of an outcome-based perspective for marriage and family therapy education. Family Process, 44(3), 355-362.

Nichols, M. P., \& Schwartz, R. C. (2001). Family therapy: Concepts and methods (5th ed). Boston, MA: Allyn \& Bacon.

Perosa, L. M., \& Perosa, S. L. (2010). Assessing competencies in couples and family therapy/counseling: A call to the profession. Journal of Marital and Family Therapy, 36(2), 126-143.

Pote, H., Stratton, P., Cottrell, D., Shapiro, D., \& Boston, P. (2003). Systemic family therapy can be manualized: Research process and findings. Journal of Family Therapy, 25, 236-262.

Rojano, R. (2004). The practice of community family therapy. Family Process, 43, $59-77$.

Smith, E. J. (2006). The strength-based counselling model. The Counselling Psychologist, 34(1), 13-79.

Smith, R. L., \& Southern, S. (2005). Integrative confusion: An examination of integrative models in couple and family therapy. The Family Journal, 13, 392-399.

Sousa, L., Ribeiro, C., \& Rodrigues, S. (2007). Are practitioners incorporating a strengths-focused approach when working with multi-problem poor families? Journal of Community \& Applied Social Psychology, 17, 53-66.

Strong, T. (2002). Collaborative "expertise" after the discursive turn. Journal of Psychotherapy Integration, 12(2), 218-232. 
APPENDIX A

LIST OF ITEMS INCLUDED IN SCALE 1- SCALE FOR THE EVALUATION OF RECEPTION AND ASSESSMENT SKILLS

\begin{tabular}{|c|c|}
\hline Item & Item description \\
\hline & The practitioner: \\
\hline 1. & $\begin{array}{l}\text { Clarifies that intervention should only proceed with the family's agreement } \\
\text { and clearly asks for its consent to collaborate with the team. }\end{array}$ \\
\hline 2. & $\begin{array}{l}\text { Clarifies the roles of the family and the team as well as the collaborative } \\
\text { nature of the relationship (mentions complementary skills; mentions that } \\
\text { the team expects the family to complete the work together and the positive } \\
\text { and negative aspects, providing its honest opinion). }\end{array}$ \\
\hline 3. & $\begin{array}{l}\text { Clarifies the family's and the team's relationship with other professionals and } \\
\text { organizations, as well as the team's working contract conditions; clarifies } \\
\text { roles, responsibilities, channels of communication and articulation, and } \\
\text { limits of confidentiality, and asks if the family is willing to accept those } \\
\text { conditions. }\end{array}$ \\
\hline 4. & $\begin{array}{l}\text { Clarifies the request (when the family does not have its own request, } \\
\text { suggests its involvement in a period of assessment and experimentation in } \\
\text { order to define a request). }\end{array}$ \\
\hline 5. & $\begin{array}{l}\text { Explores family's competencies and strengths and tries to amplify them, } \\
\text { reflecting the information to the family, helping it explore its relation and } \\
\text { meanings in family functioning. }\end{array}$ \\
\hline 6. & $\begin{array}{l}\text { Anticipates and discusses difficulties which may be associated with the } \\
\text { collaboration with the team and demonstrates interest in finding ways to } \\
\text { overcome them. }\end{array}$ \\
\hline 7. & $\begin{array}{l}\text { Discusses the referral information in a neutral, non-judgmental way, showing } \\
\text { a genuine interest in learning about the family's perception and opinions } \\
\text { about such information. }\end{array}$ \\
\hline 8. & $\begin{array}{l}\text { Helps the family project into the future to define projects, dreams, and } \\
\text { objectives; asks the family about what could be considered desired } \\
\text { outcomes of the collaboration with the team. }\end{array}$ \\
\hline 9. & Explores prior attempts to deal with the problems. \\
\hline 10. & $\begin{array}{l}\text { Frames problems in a relational or circular way and/or externalizes problems } \\
\text { (or their effects as well as constraining or potentiating factors) exploring } \\
\text { the family relation with them. }\end{array}$ \\
\hline 11. & $\begin{array}{l}\text { Discusses with the family ways to guarantee the child's safety, negotiating } \\
\text { conditions for the collaboration to proceed. }\end{array}$ \\
\hline 12. & $\begin{array}{l}\text { Maps the problems and dominant meanings and explores the relational } \\
\text { patterns which hold the problems and contextual influences. }\end{array}$ \\
\hline
\end{tabular}




\section{APPENDIX B \\ LIST OF ITEMS INCLUDED IN SCALE 2- SCALE FOR THE EVALUATION OF BASIC SKILLS}

\begin{tabular}{|c|c|}
\hline Item & Item description \\
\hline & The practitioner: \\
\hline 1. & $\begin{array}{l}\text { Provides opportunity for all family members to participate and contributes to } \\
\text { make information circulate in a neutral/multi-positioned way. }\end{array}$ \\
\hline 2. & $\begin{array}{l}\text { Avoids technical discourse and jargon and tries to incorporate the family } \\
\text { language/expressions. }\end{array}$ \\
\hline 3. & $\begin{array}{l}\text { Encourages mutual support and positive interactions between family } \\
\text { members, seeking to facilitate an open and clear communication. }\end{array}$ \\
\hline 4. & $\begin{array}{l}\text { Stimulates reflection and the construction of alternatives (privileges reflexive } \\
\text { and open questions). }\end{array}$ \\
\hline 5. & Summarizes main points of discussion and helps to structure information. \\
\hline 6. & $\begin{array}{l}\text { Confirms how his/hers messages are perceived by the family (clarifies the } \\
\text { content of the message; clarifies intentions; recognizes its mistakes). }\end{array}$ \\
\hline 7. & $\begin{array}{l}\text { Proposes activities or exercises which may illustrate present family } \\
\text { functioning or promote the rehearsal of alternatives. }\end{array}$ \\
\hline 8. & $\begin{array}{l}\text { Conveys concern, involvement, and interest for the family (shows an } \\
\text { empathic stance; uses expressions which communicate understanding; } \\
\text { makes interested questions; reflects emotions). }\end{array}$ \\
\hline 9. & $\begin{array}{l}\text { Marks the sessions with an optimistic tone and a discourse focused on } \\
\text { solutions, exceptions and focus on the future, helping the family develop } \\
\text { them. }\end{array}$ \\
\hline 10. & $\begin{array}{l}\text { Ends the sessions with an integration of the main topics or leaving a message } \\
\text { which may contribute to open alternatives in the family's functioning. }\end{array}$ \\
\hline 11. & Uses humor in difficult situations. \\
\hline 12. & Adopts a collaborative stance and discourse. \\
\hline 13. & $\begin{array}{l}\text { Shows at ease and flexibility and deals creatively and comfortably with } \\
\text { unexpected or embarrassing situations; corrects mistakes naturally. }\end{array}$ \\
\hline 14. & $\begin{array}{l}\text { States and clearly defines the session's objective; clearly presents the working } \\
\text { proposals in structured sessions. }\end{array}$ \\
\hline 15. & $\begin{array}{l}\text { Is creative in the recruitment of examples and in the adaptation of the } \\
\text { activities to suite the family. }\end{array}$ \\
\hline 16. & $\begin{array}{l}\text { Naturally responds to eventual confrontations from the family with } \\
\text { tranquility, adopting an empathic stance, avoiding confrontations and } \\
\text { quickly positioning as an ally. }\end{array}$ \\
\hline 17. & $\begin{array}{l}\text { Acts collaboratively towards the other team member, supporting and } \\
\text { complementing his/hers interventions. }\end{array}$ \\
\hline
\end{tabular}


APPENDIX C

LIST OF ITEMS INCLUDED IN SCALE 3- SCALE FOR THE EVALUATION OF SUPPORT FOR CHANGE SKILLS

\begin{tabular}{l}
\hline Item \\
\hline The practitioner: \\
Helps the family define precise and clear change objectives and a change \\
support for plan to accomplish them. \\
Promotes a negotiated definition of objectives. \\
Anticipates difficulties and obstacles and ways to overcome them (recognizes \\
and anticipates the difficulties and obstacles presented by the family; \\
involves the family in a joint problem-solving process). \\
Proposes a trial period in case the family is uncertain or insecure about the \\
proposals to facilitate change presented by the team. \\
Notes, reinforces, and amplifies family's competencies relating them to the \\
objectives to be achieved in different areas of change (focuses on solutions \\
and supports expressions of self-efficacy; amplifies moments of mastery in \\
family functioning and/or moments of exceptions to problems; recruits \\
successful and satisfactory episodes and experiences; promotes the \\
construction of a sense of authorship; discusses family's strengths and \\
bridges them with the process of change). \\
Helps and supports the family in the search and construction of moments of \\
exceptions and alternative to problems (encourages the search and \\
construction of moments in which alternative behaviors, cognitions and \\
discourses may emerge, exploring, and amplifying them; seeks to promote \\
openings in family functioning, inviting the family to work in the realm of \\
possibilities). \\
Creates conditions for the practice of the skills discussed (encourages home \\
practice proposing tasks and activities and questioning the family about its \\
evolution; provides feedback about the situations reported by the family \\
and the accomplishment of the tasks). \\
Seeks to reframe the family's problems in a more positive and flexible way. \\
Helps the family define clear boundaries between its sub-systems and in \\
relation to other systems. \\
Approaches the difficulties of family members avoiding internalization and \\
normalizing them, whenever possible. \\
Integrates the different areas of family functioning that are the focus of \\
attention and the different activities proposed.
\end{tabular}

